Uganda Journal of Agricultural Sciences by National Agricultural Research Organisation is licensed under a Creative Commons Attribution 4.0 International License. Based on a work at www.ajol.info

\title{
Effect of packaging methods on the storage stability of dried capelin under simulated temperature and humidity conditions
}

\author{
S.E. Tinyiro' ${ }^{1}$ M. G. Karlsdóttir ${ }^{2}$, P. E. Wasik ${ }^{2}$ and M. Masette $^{1}$ \\ ${ }^{1}$ Food Biosciences and Agribusiness Research Programme, National Agricultural Research \\ Laboratories, P. O. Box 7852, Kampala, Uganda \\ ${ }^{2}$ Matis Ltd, Food and Biotech R and D, Vinlandsleid 12, 113 Reykjavik, Iceland
}

Author for correspondence: stinyiro@yahoo.com

\begin{abstract}
Small pelagic fish have grown in importance for the food and nutrition security of people in developing countries. The goal of this study was to improve the storage stability of dried small pelagic fish (Capelin - Mallotus villosus) using appropriate packaging methods. Commercially dried capelin was packaged using conventional air packaging (AP), vacuum packaging (VP), modified atmosphere packaging (MAP, 99.9\% $\mathrm{N}_{2}$ ) and hessian bags (HB) before storage at simulated temperature and humidity conditions of Uganda (relative humidity $\mathrm{H}^{\prime} 54$ and 83\%; temperature $\mathrm{H}$ " 30 and $17^{\circ} \mathrm{C}$, respectively) for 8 weeks. Chemical and microbiological stability of the dried capelin was assessed with respect to packaging methods. Water content and water activity increased significantly $(p<0.05)$ for the $\mathrm{HB}$ packed capelin $(12.7-17.6 \%$ and 0.6 0.7 , respectively). Lipid content decreased significantly $(p<0.05)$ towards the end of storage in the HB packed dried capelin. Primary lipid oxidation (peroxide value) was lowest in the vacuum packed dried capelin (31.5 - 53.5 ìmol kg-1). Secondary lipid oxidation (TBARS) decreased significantly $(p<0.05)$ with storage time in the modified atmosphere packed dried capelin (250.3 - $\left.152.9 \mathrm{imol} \mathrm{MDA} \mathrm{kg}^{-1}\right)$. Free fatty acid content of dried capelin increased throughout storage irrespective of the packaging method. Total microbial count decreased significantly $(p<0.05)$ in the vacuum packed dried capelin $\left(4.8-3.6 \log \mathrm{cfu}^{-1}\right)$; while mould counts increased significantly $(\mathbf{p}<0.05)$ in the HB packed dried capelin $\left(1.0-3.0 \mathrm{log}\right.$ cfu $\left.^{-1}\right)$. VP and MAP enhanced the storage stability of dried Capelin.
\end{abstract}

Key words: Lipid oxidation, Mallotus villosus, vacuum packaging 


\section{Introduction}

Small pelagic fish are utilised largely for production of fish meal, oil and animal feeds. However, they have grown in importance for the food and nutrition security of people in developing countries, especially in Africa and Asia (Tacon and Metian, 2009). They are an affordable source of protein, omega- 3 fatty acids and micronutrients (Eyo, 2001; Tacon and Metian, 2013). More than half of the population in Sub-Saharan Africa obtains at least $25 \%$ of its protein requirements from small pelagic fish (Tacon and Metian, 2009). In Uganda, the importance of small pelagic fish cannot be understated. According to the Ministry of Agriculture Animal Industry and Fisheries (MAAIF, 2011), small pelagic fish contributed 210,000 metric tonnes of the 460,000 metric tonnes total fish production. However, based on extrapolated average retail prices, this was equivalent to approximately $20 \%$ of the estimated total production value of US\$ 1.2 billion. The main species based on catch and market value were Rastrineobola argentea (Mukene), Brycinus nurse (Ragogi) and Neobola bredoi (Muziri) (MAAIF, 2011; Taabu-Munyaho et al., 2012). The small pelagic fish are vital for the domestic as well as regional markets, in part due to a decline in large pelagic fish catches.

Post-harvest losses of small pelagic fish (40 - 90\%) continue to persist due to poor processing and limited handling capacity of large quantities landed, as well as poor packaging and storage practices (Masette, 2012). Small pelagic fish are traditionally preserved by open sun-drying, a process which is dependent on prevailing weather conditions (Masette, 2011). Dried food has a long shelf life and is generally regarded among the safest for human consumption (Calicioglu et al., 2002; Dewi et al., 2011). However, final product moisture content varies considerably with the traditional method of drying (Ofulla $e t$ al., 2011). This makes the products susceptible to mould growth and mycotoxin contamination (Kilic, 2009). Many of these are airborne moulds that infest dried fish, which is often left unpackaged after processing in developing countries (Park, 2014; Odoli, 2015).

Small pelagic fish in Uganda have high fat content in the range of $9-14 \%$ (Masette, 2014). Fish oils contain high content of long-chain unsaturated fatty acids. This predisposes them to oxidative and hydrolytic degradation (Bragadóttir et al., 2002). More so, packaging of dried fish remains largely rudimentary in many developing countries, particularly in Africa. The commonly used packaging materials are mainly; sacks, paper cartons, wooden and bamboo baskets (Abolagba and Nuntah, 2011). In addition, the tropical region is characterised by high ambient temperature and relative humidity (Kottek. et al., 2006). Such conditions, in the absence of proper packaging, provide a conducive environment for deteriorative effects of microorganisms, oxidative and enzymatic reactions (Petersen et al., 1999). Consequently, it is necessary to apply proper packaging solutions in order to ensure the shelf stability of dried small pelagic fish.

The objective of this study was to evaluate the effectiveness of different packaging methods namely; (a) air, (b) vacuum, (c) modified atmosphere, and (d) hessian bag; on the shelf life of dried capelin stored under simulated ambient conditions in Uganda. 


\section{Materials and methods}

\section{Materials}

Dried whole capelin was used for the study. Frozen whole capelin in blocks (26 $\mathrm{kg}$ ) was purchased from Sildarvinnslan hf. (Neskaupsstadur, Iceland). It was caught on 07.02.2015, plate frozen and stored at $-20{ }^{\circ} \mathrm{C}$ until processing on 16.11 .2015 . The capelin was dried by a local fish processor using geothermal energy (Haustak hf., Reykjanes, Iceland). Polythene pouches ( $350 \mathrm{~mm}$ by $500 \mathrm{~mm}$ by $90 \mu \mathrm{m}$ ) were used for Modified Atmosphere Packaging (MAP), and Vacuum Packaging (VP). Conventional polythene pouches $(350 \mathrm{~mm}$ by $500 \mathrm{~mm}$ by $30 \mu \mathrm{m}$ ) were used for air packaging (AP). Hessian bags (HB) were purchased from Haustak hf (Reykjanes, Iceland). Industrial Nitrogen gas (99.9\% purity) was purchased from AGA ehf. (Reykjavik, Iceland) and used for MAP.

All chemicals used during analysis of samples were of analytical grade, and purchased from Fluka (Buchs, Switzerland) or Sigma-Aldrich (Steinheim, Germany / St. Louis, MO, USA).

\section{Sample preparation and storage conditions}

The frozen capelin was thawed overnight at $0-2{ }^{\circ} \mathrm{C}$. The commercial drying was done using geothermal energy as described by Arason (2003). The dried capelin was then divided into 4 groups based on packaging method; air, hessian bag, vacuum and MAP. Dried capelin in the respective packages was stored under temperature and humidity modelled on Uganda's climatic condition in a specialised storage chamber $(1 \mathrm{~m} \mathrm{x} 1 \mathrm{~m} \mathrm{x}$ $2 \mathrm{~m})$ at Matis laboratories for 8 weeks. All samples were placed on two wire shelves in the middle of the chamber. Day $\left(30{ }^{\circ} \mathrm{C}, \mathrm{RH} 54 \%\right)$ and night $\left(17^{\circ} \mathrm{C}\right.$; RH
$83 \%$ ) conditions were alternated every 24 hours, and monitored by temperature and humidity data loggers (ibutton Micro-T DS1923, Dayton, OH, USA). The chemical and microbiological stability of the dried capelin was monitored during 8 weeks of storage.

\section{Packaging methods}

Vacuum packaging (VP) of dried whole capelin involved evacuating the $90 \mu \mathrm{m}$ polythene pouches ( $99.9 \%$ vacuum) before automatic heat sealing. For MAP, a modified method of Arashisar et al. (2004) was used. The polythene pouches were evacuated (99.9\% vacuum) before flushing with industrial nitrogen gas $(99.9 \%$ purity) to give a final volume ratio of approximately 2:1 (gas: capelin) prior to automatic heat-sealing. A multipurpose vacuum packaging machine (Webomatic C10-H, Bochum, Germany) was used for vacuum and MAP packaging. In Air packaging (AP), polythene pouches (30 $\mu \mathrm{m})$ containing dried capelin and normal atmospheric gas mixture were folded at the open end for a loose seal. Hessian bags (340 $\mathrm{mm} \times 560 \mathrm{~mm}$ ) containing dried capelin were fastened using hessian strings. All packages were then transferred to the storage chamber.

\section{Chemical analysis}

Approximately $300 \mathrm{~g}$ of dried capelin from each group was minced and used for all chemical analyses. All samples were analysed in triplicate $(n=3)$. Any deviations from this protocol are included in the methods description.

Water content was determined gravimetrically (by the weight difference) during drying of a $5 \mathrm{~g}$ minced capelin at $104{ }^{\circ} \mathrm{C} \pm 1{ }^{\circ} \mathrm{C}$ for $4 \mathrm{hr}$ (ISO 6496, 1999). Results were calculated as $\mathrm{g}$ water per $100 \mathrm{~g}$ sample. Water activity was 
measured using a water activity meter (Aqua Lab, 4TE, Decagon Devices Inc., USA). Colour was analysed using Minolta Chroma meter CR-400 (Minolta Co., Ltd; Osaka, Japan). Colour measurements entailed: the $L$ value, lightness on the scale of 0 to 100 from black to white; $a$ value, (+) red or (-) green; $b$ value, (+) yellow or (-) blue. The colour was measured at three points of the minced capelin. The $\mathrm{pH}$ of dried capelin was evaluated using a method described by Bragadottir et al. (2007). The $\mathrm{pH}$ of samples was measured using a digital $\mathrm{pH}$ meter (Knick-Portamess 913 $\mathrm{pH}$, Berlin, Germany). All samples were measured at room temperature $(22 \pm 2$ $\left.{ }^{\circ} \mathrm{C}\right)$.

Total lipids (TL) of the fish samples were extracted according to the method of Bligh and Dyer (1959). The lipid content was determined gravimetrically and results expressed as g lipid per $100 \mathrm{~g}$ of the sample. Peroxide value (primary lipid oxidation) was determined using a method described by Shantha and Decker (1994). The method of Lemon (1975) was used to determine the thiobarbituric acid reactive substances (TBARS, secondary lipid oxidation). The results were expressed as ìmol of malonaldehyde diethyl acetal per kg of dry muscle.

Free fatty acids content (FFA) was determined by the method of Bernardez et al., (2005). A total of $3 \mathrm{~mL}$ of the lipid extract (Bligh and Dyer 1959) were transferred into a screw cap tube. All residual solvent was then evaporated using nitrogen jet at $55^{\circ} \mathrm{C}$ for $5-10$ mins. The solvent-free lipid in the tubes was allowed to cool to ambient temperature and, to it was added $3 \mathrm{~mL}$ of cyclohexane; followed by $1 \mathrm{~mL}$ of cupric acetate - pyridine reagent. The two phase system was vortexed for 30s; followed by centrifugation at $2000 \mathrm{~g}$ for $10 \mathrm{~min}$ at 4 ${ }^{\circ} \mathrm{C}$. The absorbance of the upper layer was read at $710 \mathrm{~nm}$ (UV-1800 spectrophotometer, Shimadzu, Japan). The concentration of FFA was calculated as ìmol oleic acid based on a standard curve spanning a 2 - 22 ìmol range. Results were expressed as grams FFA per 100 grams of total lipids.

\section{Microbiological analysis}

Microbiological parameters included analysis of aerobic plate count (TPC), moulds and yeast count according to (Cyprian et al., 2017). The results were expressed as log CFU per gram minced sample.

\section{Statistical analysis}

Dried samples (approximately $300 \mathrm{~g}$ each) obtained from the different packaging methods were analysed at $0,2,4,6$ and 8 weeks of storage. All samples were analysed in triplicate $(n=3)$.

The statistical analysis system software package SAS (Version 9.3, 2011; SAS Institute Inc., Cary, NC, USA) was used for analysis of data. One-way ANOVA was used to compare data sets with Duncan's multiple range test. The significance level was set at $\mathrm{p}<0.05$. Furthermore, calculation of Pearson's correlation coefficients between different variables was performed using Microsoft Office Excel 2013 (Microsoft Inc., Redmond, USA).

\section{Results}

\section{Water content and activity}

The water content of the dried capelin fluctuated among AP, VP, MAP and HB throughout the storage period; and was in the range $11.4-17.6 \%$ (Table 1). The water content of the dried capelin in the 
Table 1. Water content of dried capelin during the 8 weeks storage $(\mathrm{RH} \sim 54-83 \%$; Temperature $\sim 17-30{ }^{\circ} \mathrm{C}$ ) using AP, VP, MAP and HB packaging

\begin{tabular}{|c|c|c|c|c|}
\hline \multirow[t]{2}{*}{ Storage time (Weeks) } & \multicolumn{4}{|c|}{ Water content $(\%)$} \\
\hline & AP & VP & MAP & HB \\
\hline 0 & ${ }^{\mathrm{aB}} 12.70 \pm 0.00$ & ${ }^{\mathrm{aA}} 12.70 \pm 0.00$ & ${ }^{\mathrm{aA}} 12.70 \pm 0.00$ & ${ }^{\mathrm{aD}} 12.70 \pm 0.00$ \\
\hline 2 & ${ }^{\mathrm{bC}} 12.15 \pm 0.07$ & ${ }^{\mathrm{bB}} 11.90 \pm 0.00$ & ${ }^{\mathrm{cC}} 11.4 \pm 0.14$ & ${ }^{\mathrm{aC}} 15.65 \pm 0.07$ \\
\hline 4 & bB $12.85 \pm 0.21$ & св $11.95 \pm 0.07$ & ${ }^{\mathrm{cbBA}} 12.35 \pm 0.07$ & aA $17.60 \pm 0.14$ \\
\hline 6 & ${ }^{\mathrm{bc}} 12.05 \pm 0.07$ & ${ }^{\mathrm{bB}} 12.00 \pm 0.14$ & ${ }^{\mathrm{bB}} 12.00 \pm 0.14$ & ${ }^{\mathrm{aB}} 16.75 \pm 0.07$ \\
\hline 8 & ${ }^{\mathrm{bA}} 13.75 \pm 0.07$ & ${ }^{\mathrm{cA}} 12.55 \pm 0.21$ & ${ }^{\mathrm{cA}} 12.65 \pm 0.07$ & ${ }^{\mathrm{aCB}} 16.20 \pm 0.28$ \\
\hline
\end{tabular}

(AP - Air Packaging; VP - Vacuum Packaging; MAP - Modified Atmosphere Packaging; HB Hessian Bag)

Different letter indicates significant difference among means in the same row (lower case) and columns (upper case)

HB package increased with time and was significantly higher $(\mathrm{p}<0.05)$ compared to the other packaging methods at all sampling intervals.

Data for water activity of the dried capelin packed as VP and MAP was stable throughout storage $(0.62-0.64)$ presented in Figure 1. However, the water activity of the HB packed dried capelin increased significantly $(\mathrm{p}<0.05)$ with time.

\section{pH}

The $\mathrm{pH}$ of the dried capelin decreased gradually for the first four weeks of the storage from the initial 6.58. This was followed by slight increase in the sixth week, before decreasing again at week 8 for all packaging methods (Fig. 2). However, the variation in $\mathrm{pH}$ was not significantly different $(\mathrm{p}>0.05)$ among all packaging methods during the entire storage period, except for HB packed samples. The HB packed dried capelin attained a minimum $\mathrm{pH}$ of 6.1 which was significantly different $(\mathrm{p}<0.05)$ compared to the other packaging methods.

\section{Colour}

The colour (lightness, redness and yellowness) of the dried capelin was independent of packaging method throughout the storage period (Fig. 3). The lightness, redness and yellowness were within the range of $40.26-34.63,4.80-$ 3.43 ) and $5.51-2.43$, respectively. The lightness and redness were rather stable throughout the storage period; while the yellowness of the dried capelin increased significantly $(\mathrm{p}<0.05)$ at the second week of storage for all packaging methods before stabilising for the rest of the storage period.

\section{Lipid content}

The lipid content of the dried capelin was in the range of $37.3-25.2 \%$ throughout the storage period (Fig. 4). The lipid content showed a decreasing trend with storage time, especially after week 4; though the trend was not significant; except the HB packed samples in week 8 (25.2\%). 


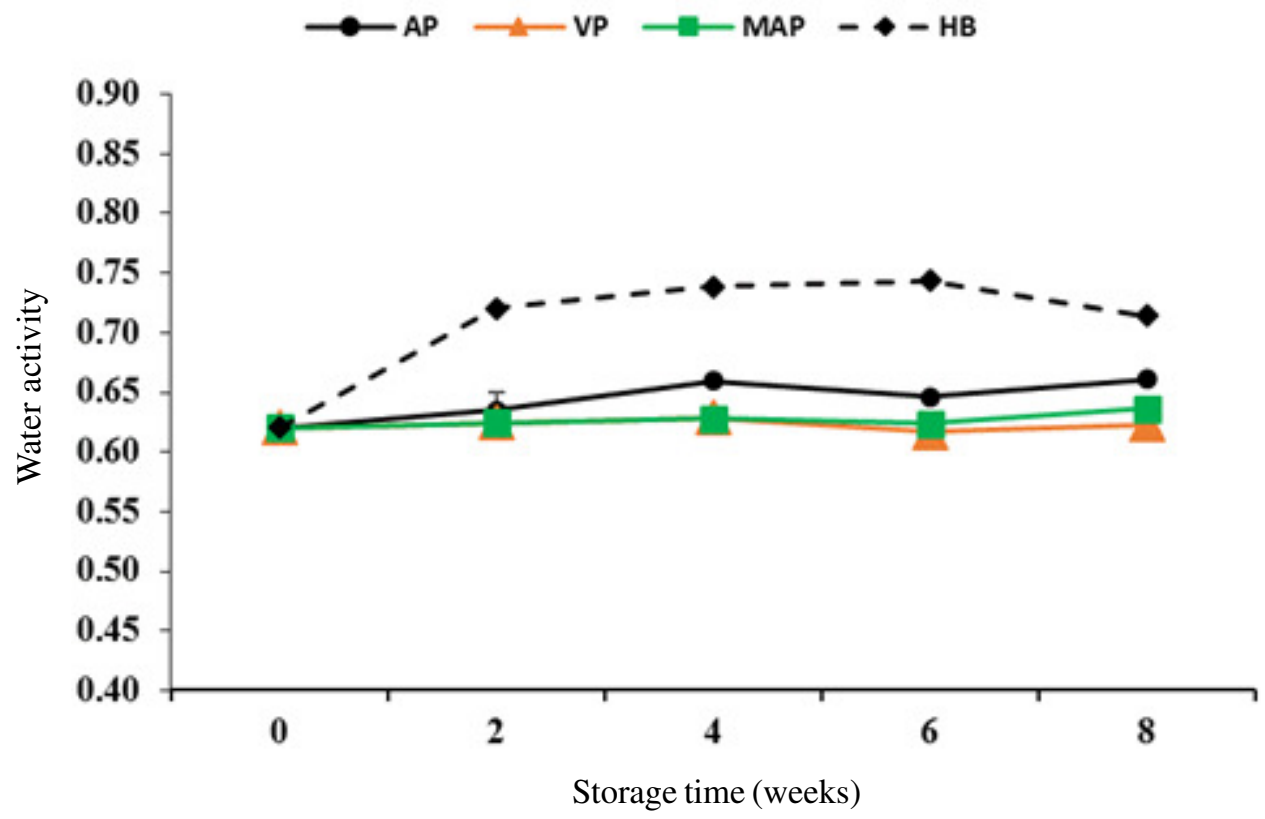

Figure 1. Water activity of dried capelin during the 8 weeks storage $(\mathrm{RH} \sim 54-83 \%$; Temperature $\sim 17-30{ }^{\circ} \mathrm{C}$ ) using air packaging (AP); vacuum packaging (VP); modified atmosphere packaging (MAP) and hessian bag (HB).

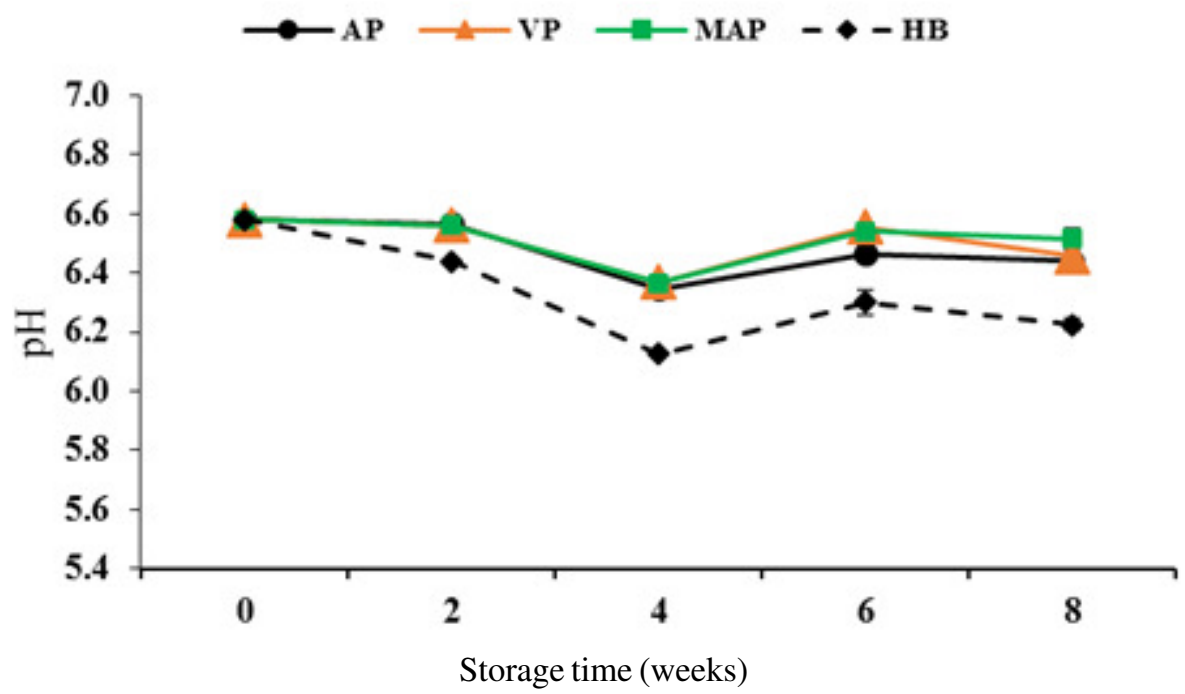

Figure 2. $\mathrm{pH}$ of dried capelin during the 8 weeks storage (RH $\sim 54-83 \%$; Temperature $\sim 17$ $-30{ }^{\circ} \mathrm{C}$ ) using air packaging (AP); vacuum packaging (VP); modified atmosphere packaging (MAP) and hessian bag (HB). 
Packaging methods on the storage stability of dried capelin
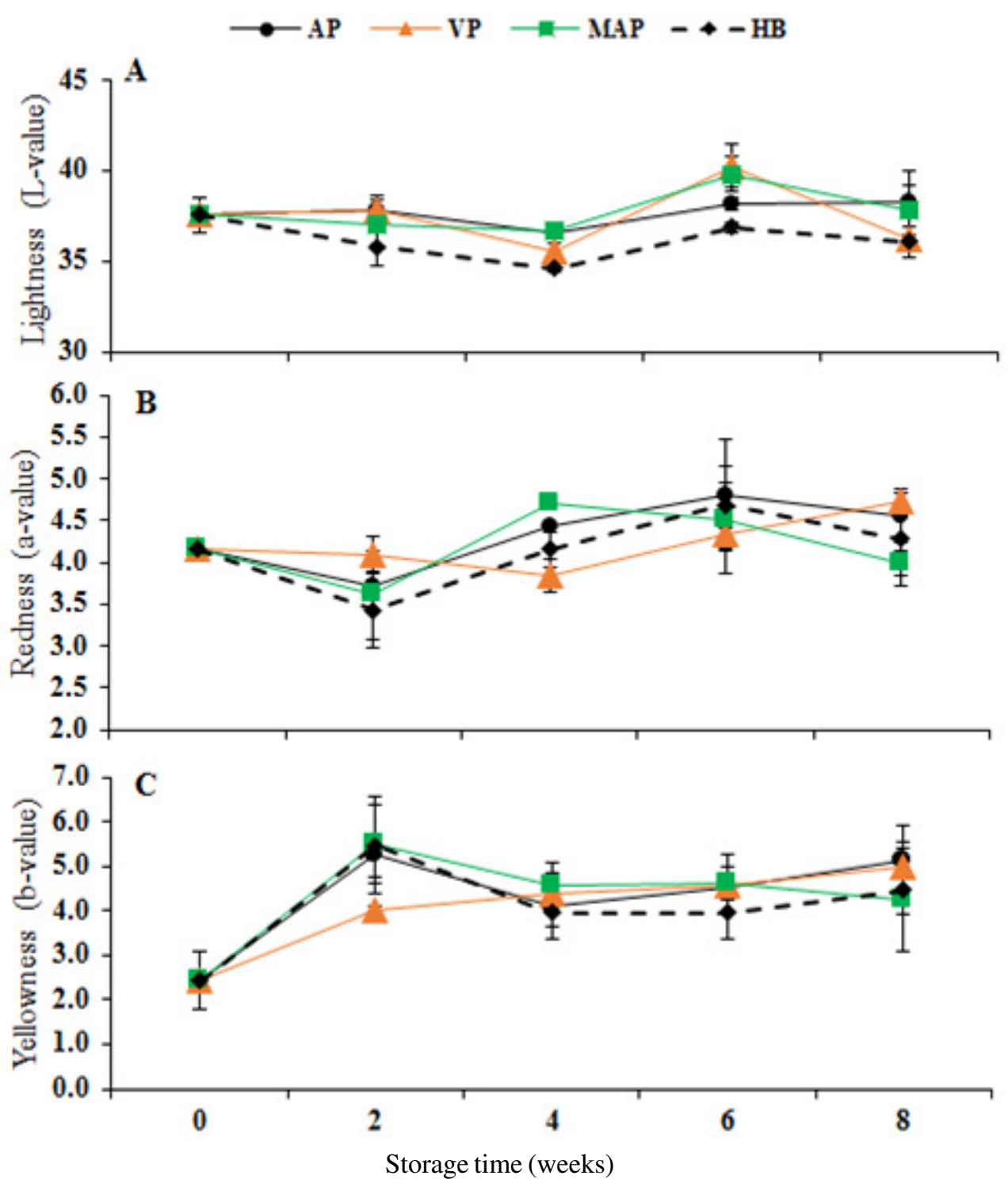

Figure 3. Lightness(A), redness $(B)$ and yellowness $(C)$ of dried capelin during the 8 weeks storage (RH $\sim 54-83 \%$; Temperature $\sim 17-30{ }^{\circ} \mathrm{C}$ ) using air packaging (AP); vacuum packaging (VP); modified atmosphere packaging (MAP) and hessian bag (HB). 


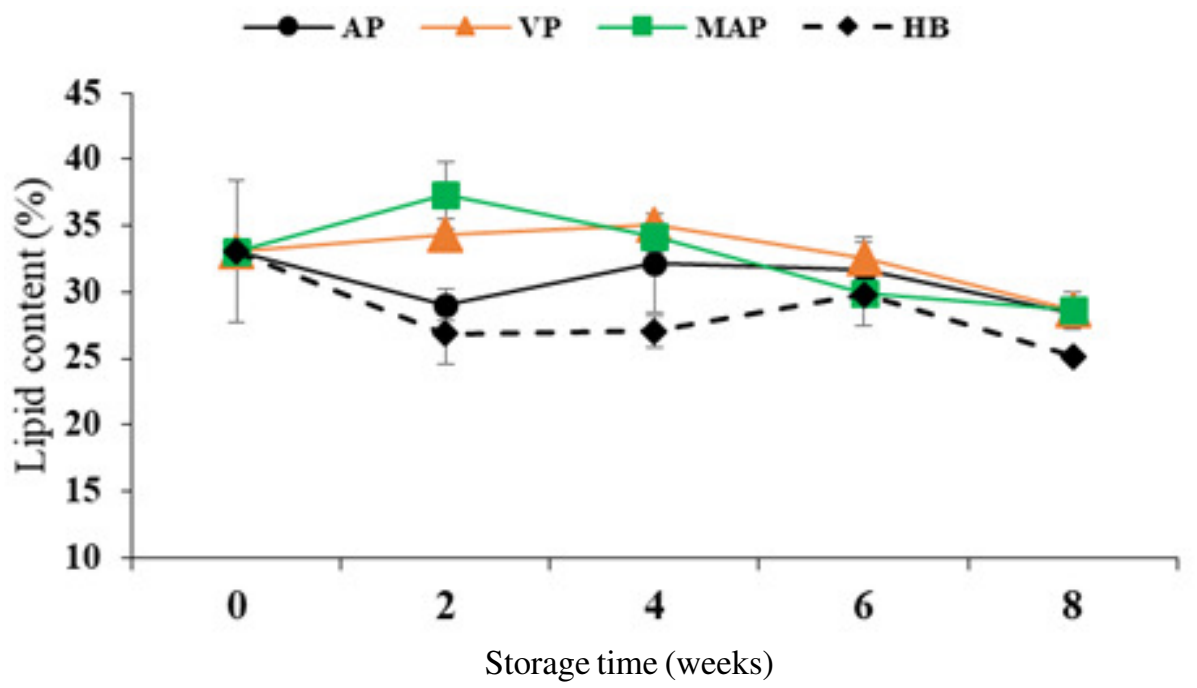

Figure 4. Lipid content $(\%)$ of dried capelin during the 8 weeks storage $(\mathrm{RH} \sim 54-83 \%$; Temperature $\sim 17-30{ }^{\circ} \mathrm{C}$ ) using air packaging (AP); vacuum packaging (VP); modified atmosphere packaging (MAP) and hessian bag (HB).

\section{Peroxide value}

The peroxide value (PV) of the dried capelin varied with packaging method from 31.5 to $149.5 \mathrm{imol} \mathrm{kg}{ }^{-1}$ (Fig. 5). The PV increased significantly $(\mathrm{p}<0.05)$ during the first two weeks of storage for the MAP, AP and HB packed samples in ascending order. The PV then decreased significantly $(\mathrm{p}<0.05)$ at week 4 for the MAP, AP and HB packed samples and did not vary significantly from this point to the end of storage time. The PV of the VP packed dried capelin were stable throughout storage $(p>0.05)$.

\section{Thiobarbituric acid reactive substances}

The Thiobarbituric acid reactive substances (TBARS) content of the dried capelin varied with packaging methods (Fig. 6). Generally, the TBARS content decreased during the storage, for all packaging methods, with the exception of AP packed samples. The TBARS content of the AP packed dried capelin increased during the first four weeks of the storage before decreasing in the remaining four weeks. The highest TBARS content (313 ìmol $\mathrm{MDA} \mathrm{kg}{ }^{-1}$ ) was recorded for the $\mathrm{AP}$ packed samples at week 4 and was significantly different $(\mathrm{p}<0.05)$ compared to the other packaging methods. The lowest TBARS content (152.85 ìmol MDA $\mathrm{kg}^{-1}$ ) was obtained in the MAP packed samples at the end of the storage period. The TBARS content of the MAP packed dried capelin decreased throughout storage and was significantly lower $(\mathrm{p}<0.05)$ compared to the other methods.

\section{Free fatty acid content}

The free fatty acid (FFA) content of dried capelin increased significantly throughout the storage period, regardless of packaging method (Fig. 7). The highest FFA content

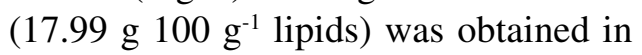
the HB packed dried capelin $(\mathrm{p}<0.05)$. 


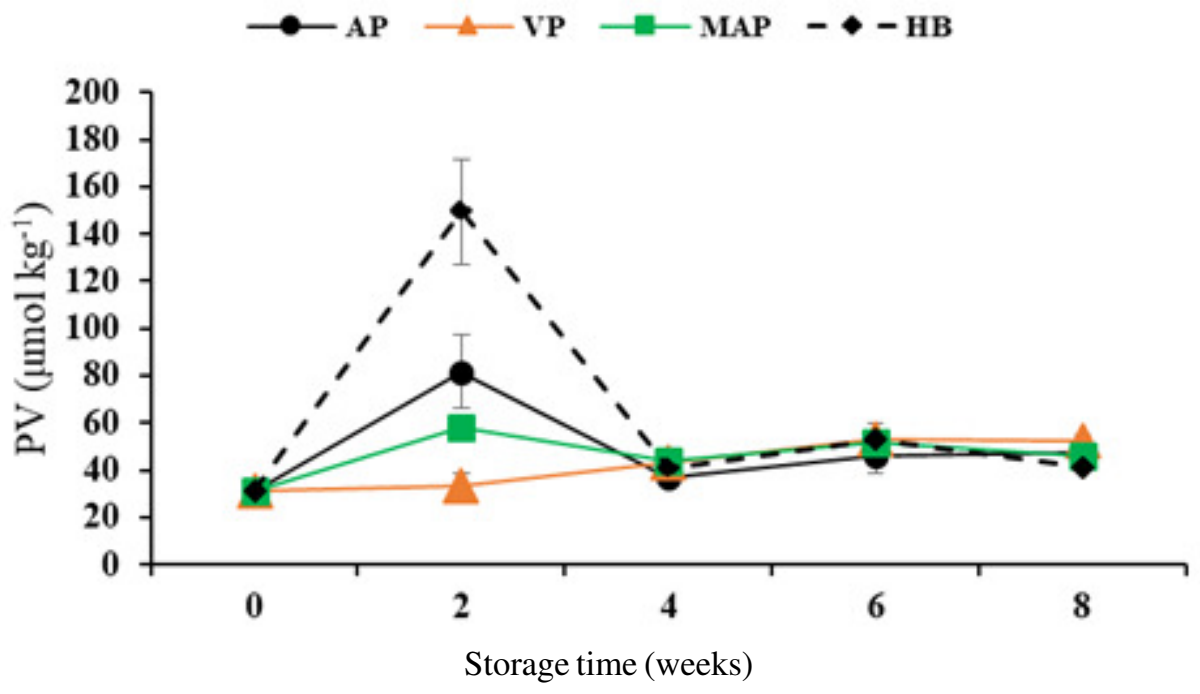

Figure 5. Peroxide value (PV; $\mu \mathrm{mol} \mathrm{kg}{ }^{-1}$ sample) of dried capelin during the 8 weeks storage (RH 54 - 83\% ; Temperature 17 - 30 ${ }^{\circ} \mathrm{C}$ ) using air packaging (AP); vacuum packaging (VP); modified atmosphere packaging (MAP) and hessian bag (HB).

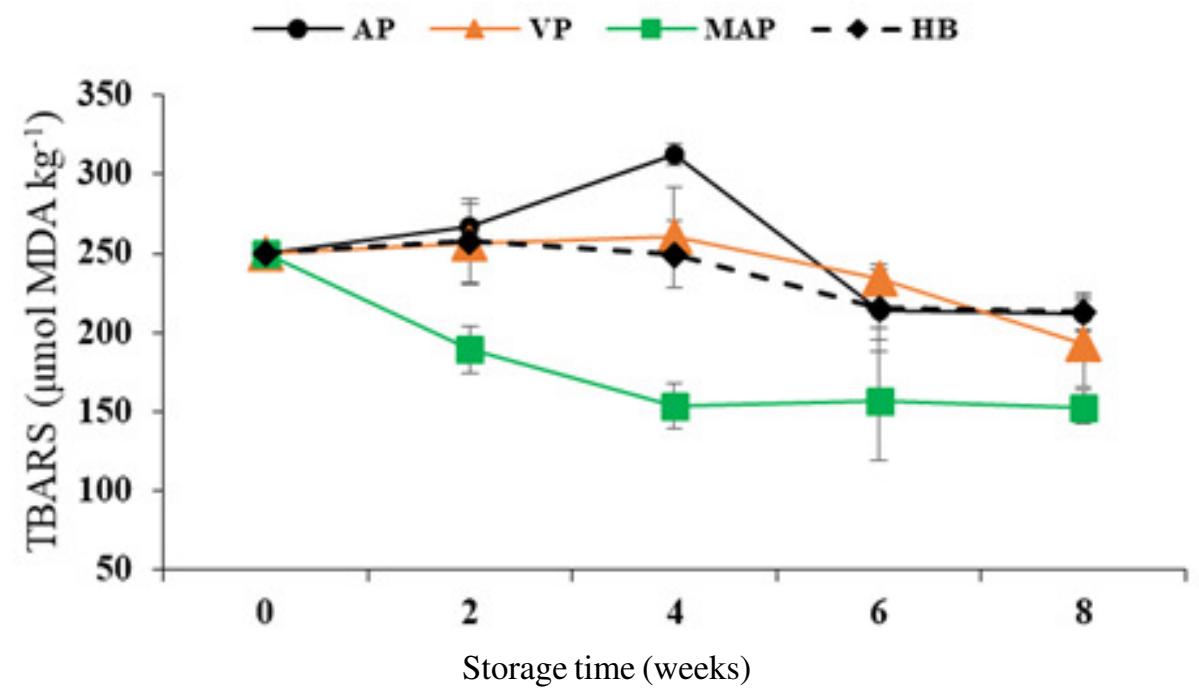

Figure 6. Thiobarbituric acid reactive substances (TBARS; $\mu \mathrm{mol} \mathrm{MDA} \mathrm{kg-1}$ sample) of dried capelin during the 8 weeks storage (RH $\sim 54-83 \%$; Temperature $\sim 17-30{ }^{\circ} \mathrm{C}$ ) using air packaging (AP); vacuum packaging (VP); modified atmosphere packaging (MAP) and hessian bag (HB). 


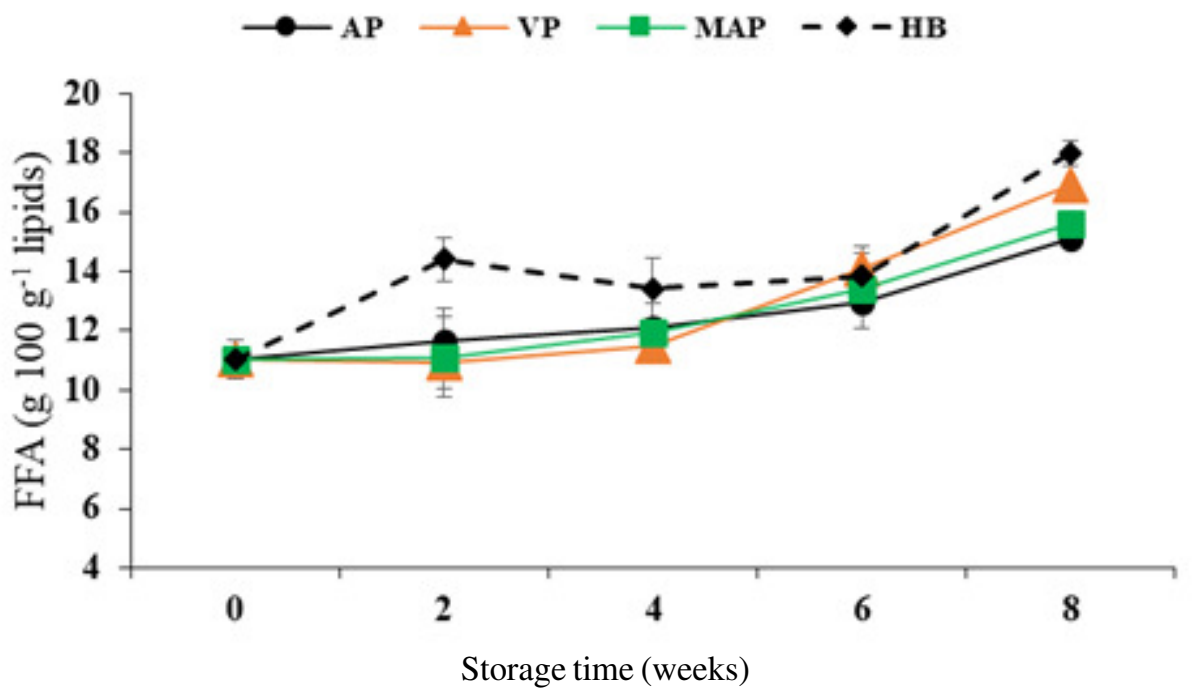

Figure 7. Free fatty acid content ( $\mathrm{g} \mathrm{FFA} 100 \mathrm{~g}^{-1}$ lipids) of dried capelin during the 8 weeks storage (RH $\sim 54-83 \%$; Temperature $\sim 17-30{ }^{\circ} \mathrm{C}$ ) using air packaging (AP); vacuum packaging (VP); modified atmosphere packaging (MAP) and hessian bag (HB).

\section{Total plate count}

The total plate count (TPC) of dried capelin decreased generally with storage time for all packaging methods (Fig. 8). The TPC of the VP packed dried capelin decreased significantly $(\mathrm{p}<0.05)$ throughout the storage period resulting in the lowest counts (3.55 log $\left.\mathrm{cfu} \mathrm{g}^{-1}\right)$, whereas the highest TPC was recorded in the AP packed dried capelin (5.96 log cfu $\mathrm{g}^{-1}$ ).

\section{Yeast and mould count}

The yeast count of the dried capelin was stable for most of the storage period for all packaging methods (Fig. 9A). Yeast count of dried capelin in AP increased significantly $(\mathrm{p}<0.05)$ during the first two weeks of storage $\left(1.00-2.75 \log \mathrm{cfu} \mathrm{g}^{-1}\right)$ and decreased over the next two weeks. Mould growth was most significant in HB packed dried capelin throughout the storage period (Fig. 9B).

\section{Discussion}

\section{Water content and activity}

The observed changes in water content and water activity of the dried capelin under respective packaging methods were strongly correlated $(r=0.95)$ throughout the storage period (Table 1 and Fig. 1). The ventilated and adsorbent nature of the hessian bags resulted in a significant increase in water content and activity of capelin stored therein when relative humidity was increased over time $(\mathrm{H} " 83 \%)$. The increase in moisture content and water activity in $\mathrm{HB}$ can be explained by the adsorption and desorption behaviour of dried foods. Moisture diffusion into and out of a food product is primarily a function of vapour pressure gradient, composition and temperature (Singh and Heldman, 2014). Increase in the storage relative humidity (H"83\%) resulted in migration of moisture down the 


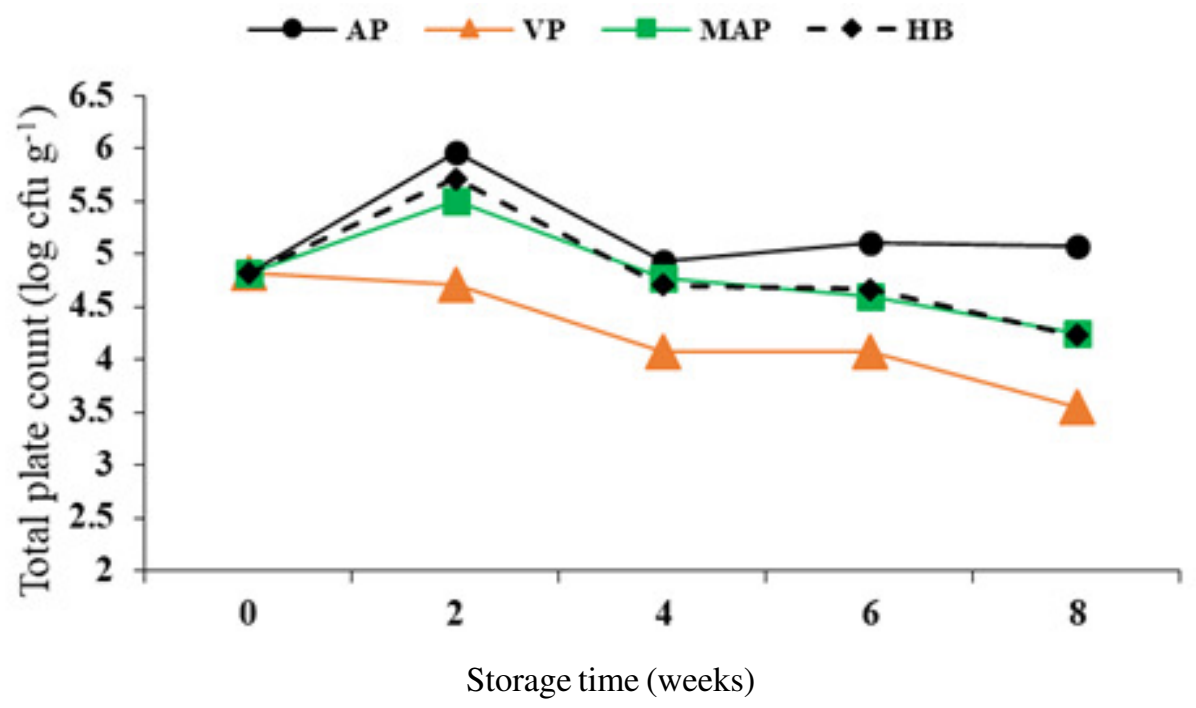

Figure 8. Total plate count (TPC; $\log \mathrm{cfu} \mathrm{g}^{-1}$ sample) of dried capelin during the 8 weeks storage (RH $\sim 54-83 \%$; Temperature $\sim 17-30{ }^{\circ} \mathrm{C}$ ) using air packaging (AP); vacuum packaging (VP); modified atmosphere packaging (MAP) and hessian bag (HB).

vapour pressure gradient into the dried capelin (water activity - 0.62) stored in the $\mathrm{HB}$ to a point of equilibrium. The reverse temperature and humidity cycle had little effect on the moisture migration because at lower relative humidity, water is tightly bound according to Sahin and Sumnu (2006). The cumulative effect of fluctuating temperature and humidity resulted in maximum equilibrium moisture content and water activity of the dried capelin in HB during the fourth week of storage. Water activity of food is important because it triggers microbial metabolism, enzymatic and chemical reactions. Generally, water activity $<0.6$ is sufficient to inhibit all microbial activity (Fellows, 2000). According to FDA (2001), dried fishery products under reduced oxygen packaging should maintain a minimum water activity of d" 0.85 to be considered safe. This prevents growth and toxin production by $S$. aureus, but more importantly the anaerobic $C$. botulinum.
Water activity above 0.7 promotes growth of halophilic bacteria and xerophilic fungi (Ray and Bhunia, 2014). According to the East African Community (EAC) standards, the maximum moisture content requirement for dried fish is $14 \%$ (EAC, 2017). All packaging methods maintained safe storage moisture content and water activity, except the HB packaging method.

\section{pH}

The $\mathrm{pH}$ of the dried capelin generally decreased during the first four weeks of the storage period, albeit insignificantly (Fig. 2). This may be linked to the increase in the FFA content since there was a strong negative correlation $(\mathrm{r}=-0.84)$ between the parameters during the storage period. The slight increase in $\mathrm{pH}$ during the latter weeks of the storage might be attributed to the development of volatile basic nitrogen compounds. Bragadóttir et al. (1998) reported an increase in total volatile nitrogen of dried 


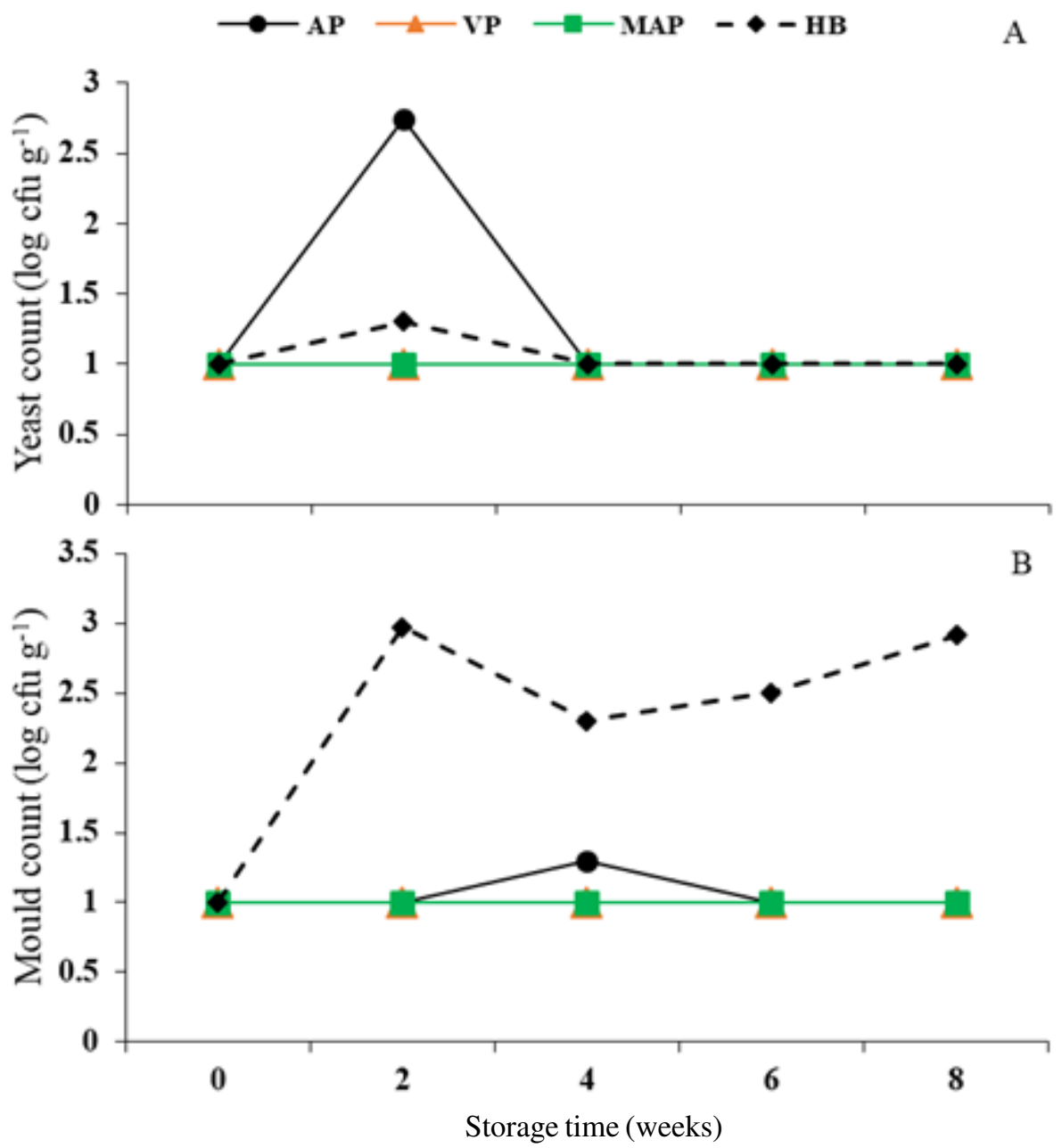

Figure 9. Yeast (A) and mould (B) count of dried capelin during the 8 weeks storage (RH $\sim 54$ - 83\% ; Temperature $17-30{ }^{\circ} \mathrm{C}$ ) using air packaging (AP); vacuum packaging (VP); modified atmosphere packaging (MAP) and hessian bag (HB).

whole capelin after one month of storage at $39^{\circ} \mathrm{C}$. A similar observation was made by Ogongo et al. (2015) during storage of vacuum and controlled atmosphere packed dried sardines. Overall, the $\mathrm{pH}$ of the dried capelin was rather stable throughout the storage period for all packaging methods.

\section{Colour}

In general, the colour of the dried capelin was stable throughout the storage period
(Fig. 3). The differences among packaging methods were insignificant throughout storage. Colour is an important indicator of the composition and quality of food products. Colour perception influences the degree of acceptability of a given product by consumers (Sahin and Sumnu, 2006). The colour of capelin is associated with its astaxanthin content. It varies from red, orange to yellow depending on season and more so feeding patterns (Bragadóttir et al., 2002). Capelin has a high percentage 
of the stable diester astaxanthins in all seasons, except during the summer (Bragadóttir, 2001). The decrease in lightness during the first four weeks of the storage might be due to the formation of unstable brown compounds. Bragadóttir et al. (2004) reported an increase in brown pigments of fish meal from capelin during early storage, followed by a decline. Secondary products of lipid peroxidation, especially malondialdehyde, react with amino-sugars to form brown heterocyclic compounds and polymers similar to melanoidins (Gómez-Sánchez et al., 1990). Redness of dried capelin did not vary significantly during storage, regardless of packaging method most likely due to the stable astaxanthin. Yellowness correlated moderately $(r=0.67)$ with the peroxide value in the first four weeks of storage. The observed trend in yellowness might therefore be associated with the formation of products of lipid oxidation.

\section{Lipid content}

The lipid content of the dried capelin was generally stable but showed a decreasing trend towards the end of the storage period especially in the HB packed samples (Fig. 4). The decrease in lipid content might be linked to greater enzymatic hydrolysis of lipids, leading to formation of free fatty acids. Lipids in fish are hydrolysed by lipase and phospholipase to yield free fatty acids (Chaijan et al., 2006). The marked increase in the FFA content (Fig. 7) during this period corroborates this assertion.

\section{Peroxide value}

The observed increase in peroxide value within the first two weeks, followed by a rapid decline during the subsequent weeks of storage in the AP and HB packed samples (Fig. 5) could be explained by the fact that lipid hydroperoxides are highly reactive and degrade rapidly to form secondary products such as aldehydes, alkyl radicals and oxo-esters (Fennema, 1996). As such, peroxides are produced in the early stages of lipid oxidation, rising to a peak before declining. These results were in agreement with the findings of Odoli (2015) who reported an increase in PV of air packed cold smoked capelin followed by a decrease during chilled storage. Oxygen is a key proponent in the development of lipid hydroperoxide (Fennema, 1996). Therefore, reduced oxygen in the VP and MAP packaging resulted in slow increase of PV compared to the AP and HB packed samples. Oxygen involved in lipid oxidation diffuses from the food surface to the interior. Residual oxygen in the muscle contributes to the build-up of peroxides, even in vacuum packed fish products (Huang and Weng, 1998). Therefore, muscle oxygen might have contributed to the gradual increase, albeit insignificant, in PV of the VP and MAP packed dried capelin during the storage. The PV was most stable in the VP dried capelin which was in agreement with the findings of Odoli (2015), where the PV of vacuum packed dried capelin was stable during storage at ambient temperature.

\section{Thiobarbituric acid reactive substances} The decrease in TBARS content of the dried capelin in VP, HB and MAP package during storage (Fig. 6) was similar to the findings of Odoli (2015). The TBARS is a widely preferred method for measuring the degree of lipid oxidation as it has been reported to correlate strongly with sensory evaluation score (Fennema, 1996). According to Fennema (1996) and Undeland et al. (1999), reduction in TBARS content is attributed to the reaction of malonaldehyde with proteins 
in an oxidising system, usually leading to formation of tertiary products of lipid oxidation. The trend of increase in the TBARS content of the AP packed capelin during the first four weeks of storage might therefore be due to greater formation of malonaldehyde. Malonaldehyde may arise from the breakdown of prostaglandin-like endoperoxides during oxidation of polyunsaturated fatty acids as reported by Pryor et al. (1976). In principle, production of substantial quantities of TBA-reactive substances is linked to fatty acids with greater degree of unsaturation (Fennema, 1996). Ogongo et al. (2015) reported an increase in TBARS of dried sardine throughout storage using various packaging methods. However, different species, storage temperature $\left(0-2{ }^{\circ} \mathrm{C}\right)$ and processing methods were used. This might have contributed to the difference in the outcome. Nitrogen is an inert gas, however it might have affected the deterioration of the secondary products of lipid peroxidation throughout the storage period in the MAP packed dried capelin.

\section{Free fatty acid content}

The FFA content of the dried capelin increased throughout the storage and was independent of the packaging method used (Fig. 7). This was in agreement with Odoli (2015) who reported an increase in FFA content of dried capelin during storage at room temperature using open, sealed and vacuum packaging. Bragadóttir et al., (1998) also reported significant increase in FFA content of dried whole capelin during an accelerated shelf life study. The FFA are products of lipid hydrolysis catalysed by lipase and phospholipase (Toyomizu et al., 1981; Pacheco-Aguilar et al., 2000). According to Chaijan et al., (2006), lipase and phospholipase activity in the muscle, digestive tract and microorganisms all contribute to increase in FFA. The FFA and the lipid content had a good negative correlation throughout the storage period $(r=-0.80)$. The greater formation of FFA in the HB packed dried capelin might be due to the increase in water content and especially water activity because water plays an important role in enzyme activation. Adawiyah et al. (2012) reported an increase in the amount of FFA resulting from lipase-catalysed lipid hydrolysis in a food model system as a result of increase in water content.

\section{Total plate count}

Microorganisms occur normally in the digestive tract, scales and skin of fish, however, fish may, in addition, be contaminated from various sources such as air, soil, water and, during handling and processing via contact by humans and equipment (Ray and Bhunia, 2014).The packaging methods evaluated in the present study influenced the microbial stability of the dried capelin during storage (Figs. 8 and 9). The initial increase in Total plate counts (TPC) of the dried capelin in $\mathrm{AP}, \mathrm{HB}$ and MAP packaging was probably due to presence of oxygen at different partial pressure. This facilitated growth of aerobic microorganisms. Unexpected increase in TPC of the MAP dried capelin was possibly due to microaerophilic microorganisms which withstand low oxygen partial pressure given that industrial nitrogen gas (H"99.9\% purity) was used. The TPC of the VP packed dried capelin decreased throughout the storage period due to unfavourable anaerobic conditions. The growth capability of microorganisms in food is dependent on the availability or the absence of oxygen and the redox potential of the food. Yeasts and moulds are 
basically aerobic which explains their proliferation in the AP and the HB packed dried capelin. The growth of yeasts in the AP packed samples at low water activity is an indicator of osmophilic yeasts whose minimum water activity is $0.6-0.7$ (Ray and Bhunia, 2014). The proliferation of moulds in the HB packed dried capelin is associated with increase in the water activity during storage (Fig. 1). According to Fellows (2000), water activity of less than 0.7 should be maintained to deter fungal activity. The continued proliferation of moulds in the HB dried capelin also alludes to possible cross contamination from the bags.

\section{Conclusion}

It is clear from this study that packaging methods greatly influence the storage stability of dried capelin at the simulated temperature and relative humidity conditions. Vacuum packaging enhances the overall storage stability of dried capelin, especially against primary lipid oxidation and microbial growth throughout the storage period. Also, modified atmosphere packaging enhances lipid stability of dried capelin as evidenced by the significant reduction in the secondary lipid oxidation products (TBARS) during the eight weeks. Air and hessian bag packaging is ineffective in preventing lipid oxidation and growth of microorganisms. More so, the water content and the water activity of the dried capelin in the HB increases significantly, leading to greater proliferation of moulds. Therefore, hessian bags are not ideal packaging materials for storage of dried capelin in conditions of high relative humidity. Free fatty acid content of the dried capelin in AP, VP, MAP and HB increase steadily during storage indicating that packaging method alone is not an effective tool for controlling lipid hydrolysis.

\section{Acknowledgement}

This study was funded by the United Nations University - Fisheries Training Programme (UNU-FTP) as part of the 6 month fisheries training programme. Laboratory analyses were conducted at Matis Ltd, Food and Biotech R and D Reykjavik, Iceland. We are grateful to the UNU-FTP, Matis Ltd and National Agricultural Research Organisation for their invaluable support.

\section{References}

Abolagba, O.J. and Nuntah, J.N. 2011. Survey on cured fish processing, packaging, distribution and marketing in Edo and Delta States. International Research Journal of Biotechnology 2(5): 103-113.

Adawiyah, D.R., Soekarto, T.S. and Hariyadi, P. 2012. Fat hydrolysis in a food model system: Effect of water activity and glass transition. International Food Research Journal, 19(2), 737-741.

Arashisar, A., Hisar, O., Kaya, M. and Yanik, T. 2004. Effects of modified atmosphere and vacuum packaging on microbiological and chemical properties of rainbow trout (Oncorynchus mykiss) fillets. International Journal of Food Microbiology 97(2):209214.

Arason, S. 2003. The drying of fish and utilization of geothermal energy/; The Icelandic experience. Geo-Heat Center Bulletin 24 (4):27-33.

Bernardez, M., Pastoriza, L., Sampedro, G., Herrera, J. J. R. and Cabo, M. L. 2005. Modified Method for the 
Analysis of Free Fatty Acids in Fish. Society 53(6):1903-1906.

Bligh, E. G., and Dyer, W. J. 1959. A rapid method of total lipid extraction and purification. Canadian Journal of Biochemistry and Physiology 37(8): 911-917.

Bragadóttir, M., Hansen, R. and Guðlaugsson, B. 1998. Enhancing the Stability and Production Economy of Salted and Dried Whole Capelin, Mallotus villosus. Icelandic Fisheries Laboratories. Report No. 08 - 98. 16pp.

Bragadóttir, M. 2001. On the stability of icelandic capelin meal. MSc Thesis, University of Iceland. 97pp.

Bragadóttir, M., Pálmadóttir, H. and Kristbergsson, K. 2002. Seasonal changes in chemical composition and quality parameters in capelin (Mallotus villosus). Journal of Aquatic Food Product Technology 11(3-4):87-103.

Bragadóttir, M., Pálmadóttir, H. and Kristbergsson, K. 2004. Composition and chemical changes during storage of fish meal from capelin (Mallotus villosus). Journal of Agricultural and Food Chemistry 52(6):15721580.

Bragadottir, M., Reynisson, E., Thorarinsdottir, K.A. and Arason, S. 2007. Stability of fish powder made from saithe (Pollachinus virens) as measured by lipid oxidation and functional properties. Journal of Aquatic Food Production Technology 16(1):211-218.

Calicioglu, M., Sofos, J.N., Samelis, J., Kendall, P. A. and Smith, G.C. 2002. Destruction of acid-and non-adapted Listeria monocytogenes during drying and storage of beef jerky. Food Microbiology 19(6):545-559.
Chaijan, M., Benjakul, S., Visessanguan, W., and Faustman, C. 2006. Changes of lipids in sardine (Sardinella gibbosa) muscle during iced storage. Food Chemistry 99(1):83-91.

Cyprian, O.O., Sveinsdottir, K., Nguyen, M.V., Tomasson, T., Thorkelsson, G., and Arason, S. 2017. Influence of lipid content and packaging methods on the quality of dried capelin (Mallotus villosus) during storage. Journal of Food Science and Technology 54(2): 293-302.

Dewi, R.S., Huda, N. and Ahmad, R. 2011. Changes in the physicochemical properties, microstructure and sensory characteristics of shark dendeng using different drying methods. American Journal of Food Technology 6:149157.

EAC. 2017. EAS 828 dried and salted dried fish - Specification. 8pp.

Eyo, A.A. 2001. Fish processing technology in the tropics. National Institute for Freshwater Fisheries Research (NIFFR), New Bussa, Nigeria. pp. 10-170.

FDA. 2001. Clostridium botulinum toxin formation. In: Fish and fishery products hazards and controls guidance. 3rd ed., Ch. 13. pp. 167-190. Food and Drug Administration, Center for Food Safety and Applied Nutrition, Office of Seafood, Washington, DC., USA.

Fellows, P.J. 2000. Food processing technology: Principles and Practice. 2nd Ed. Woodhead Publishing Limited and CRC Press LLC.

Fennema, O.R. 1996. Food Chemistry. 3rd ed. 1263pp. Marcel Dekker, Inc. 270 Madison Avenue, New York, USA.

Gómez-Sánchez, A., Hermosín, I. and Maya, I. 1990. Heterocycle formation from malondialdehyde and amino sugars. In: The Maillard reaction in 
food processing, human nutrition and physiology; Finot, P. A., Aeschbacher, H. U., Hurrel, R. F. and Liardon, R., (Eds.). pp. 139-144. Birkhäuser Verlag, Basel, Switzerla. Basel: Birkhäuser Verlag.

Huang, C.H. and Weng, Y.M. 1998. Inhibition of lipid oxidation in fish muscle by antioxidant incorporated polyethylene film. Journal of Food Processing and Preservation 22(3): 199-209.

Kilic, A. 2009. Low temperature and high velocity (LTHV) application in drying: Characteristics and effects on the fish quality. Journal of Food Engineering 91(1):173-182.

Kottek, M., Grieser, J., Beck, C., Rudolf, B. and Rubel, F. 2006. World map of the Köppen-Geiger climate classification updated. Meteorologische Zeitschrift 15(3):259-263.

Lemon, D.W. 1975. An improved TBA test for rancidity. Halifax: Fisheries and Marine Service. Canada. New Series Circular No. 51.

MAAIF. 2011. Department of Fisheries Resources Annual Report 2010/2011. Retrieved from http://www.agriculture. go.ug/userfiles/DFR Annual Report 2012.pdf

Masette, M. 2011. Product development and testing of mukene-based products: Increase supply of Mukene (Rastrineobola argentea) for human consumption. FAO Report TCP/UGA/ 3204 (D).

Masette, M. 2012. Sun-dried Mukene (Rastrineobola argentea) value-chain analysis in Uganda. In: IIFET Conference. pp. 127-136. Dar es Salaam. Retrieved from https:// ir.library.oregonstate.edu/xmlui/ bitstream/handle/1957/35407/ Masette.pdf?sequence $=1$
Masette M. 2014. Securing the nutritional value of freshwater fish products in the East, Central and Southern African region: Case study for Uganda. FAO Report. 58pp.

Odoli, C.O. 2015. Drying and smoking of capelin (Mallotus villosus) and sardine (Sardinella gibbosa): The influence on physicochemical properties and consumers acceptance. $\mathrm{PhD}$ Thesis, University of Iceland. 203pp.

Ofulla, A.V., Onyuka, J.H., Wagai, S., Anyona, D., Dida, G.O. and Gichuki, J. 2011. Comparison of different techniques for processing and preserving fish Rastrineobola. World Academy of Science, Engineering and Technology 60(12):1643-1647.

Ogongo, B.O., Odote, P.M.O. and Mlanda, M.N. 2015. Effects of vacuum-packaging on the microbiological, chemical, textural and sensory changes of the solar rack dried sardines during chill storage. Bacteriology Journal 5(1):25-39.

Pacheco-Aguilar, R., Lugo-Sánchez, M. E. and Robles-Burgueño, M.R. 2000. Postmortem biochemical and functional characteristic of Monterey sardine muscle stored at 0 C. Journal of Food Science 65(1):40-47.

Park, S.Y., Lee, N.Y., Kim, S.H., Cho, J.I., Lee, H.J. and Ha, S.D. 2014. Effect of ultraviolet radiation on the reduction of major food spoilage molds and sensory quality of the surface of dried filefish (Stephanolepis cirrhifer) fillets. Food Research International 62: 1108-1112.

Petersen, K., Nielsen, P.V., Bertelsen, G., Lawther, M., Olsen, M.B., Nilsson, N.H. and Mortensen, G. 1999. Potential of biobased materials for food 
packaging. Trends in Food Science and Technology 10(2):52-68.

Pryor, W. A., Stanley, J. P. and Blair, E. 1976. Autoxidation of polyunsaturated fatty acids: II. A suggested mechanism for the formation of TBA-reactive materials from prostaglandin-like endoperoxides. Lipids 11(5):370-379.

Ray, B. and Bhunia, A. 2014. Fundamental food microbiology. 5th Edition.. CRC press. 663pp.

Sahin, S. and Sumnu, S.G. 2006. Physical properties of foods. Springer Science and Business Media, LLC., 233 Spring Street, New York, USA. 267pp.

Shantha, N.C. and Decker, E.A. 1994. Rapid, sensitive, iron-based spectrophotometric methods for determination of peroxide values of food lipids. Journal of AOAC International 77:421-424.

Singh, R.P. and Heldman, D.R. 2014. Introduction to food engineering. $5^{\text {th }}$ Edition. Academic Press/Elsevier. 892pp.

Taabu-Munyaho, A, Mbabazi, D., Nakiyende, H., Bassa, S., Muhumuza, E., Nsega, M., Byekwaso, A., Amiina,
R. and Balirwa, J. S. 2012. Report of catch assessment survey of Lake Albert - Albert Nile conducted in July 2012. National Fisheries Resources Research Institute (NaFIRRI). 17pp. Tacon, A. G. J. and Metian, M. 2013. Fish matters: Importance of aquatic foods in human nutrition and global food supply. Reviews in Fisheries Science 21(1):22-38.

Tacon, A.G.J. and Metian, M. 2009. Fishing for feed or fishing for food: Increasing global competition for small pelagic forage fish. A Journal of the Human Environment 38(6):294-302.

Toyomizu, M., Hanaoka, K. and Yamaguchi, K. 1981. Effect of release of free fatty acids by enzymatic hydrolysis of phospholipids on lipid oxidation during storage of fish muscle at $-5^{\circ} \mathrm{C}$. Bulletin of the Japanese Society of Scientific Fisheries 47(5): 615-620.

Undeland, I., Hall, G. and Lingnert, H. 1999. Lipid oxidation in fillets of herring (Clupea harengus) during ice storage. Journal of Agricultural and Food Chemistry 47(2):524-532. 